\title{
O disfarce do ovo - reação como procedimento de criação
} para a cena contemporânea

\section{Resumo}

O texto compartilha procedimentos criativos da criação de O Disfarce do Ovo, delimitando a ideia de reação a uma obra de referência como forma de encenação do Coletivo Teatro Dodecafônico. A ideia de reação emerge como uma espécie de leitura em busca de referências cruzadas, buscando responder à obra de Clarice Lispector com uma coletânea de impressões e citações. A fricção, a justaposição, a sobreposição são escolhas da encenação, que dialoga com o procedimento cinematográfico de montagem.

Palavras-chave: reação, encenação, texto literário, corpo.

\section{Abstract}

The text shares creative procedures of creating O Disfarce do Ovo, delimiting the idea of reaction of a reference piece as a way of direction in the Coletivo Teatro Dodecafônico. The idea of reaction emerges as a kind of reading in search of cross-references, seeking to respond to the work of Clarice Lispector with a collection of quotes and impressions. Friction, juxtaposition, overlapping are the choices of staging, which is related with the procedure of cinematic montage.

Keywords: Reaction; Staging; Literary text; Body.

O Coletivo Teatro Dodecafônico² reúne artistas de diversas áreas (teatro, arquitetura, moda, vídeo, iluminação) interessados em realizar trabalho autoral em diálogo com a cena teatral contemporânea. Alguns dos elementos que permeiam suas experimentações são: a exploração de procedimentos da linguagem cinematográfica na criação teatral, a experimentação das arquiteturas de espaços não convencionais e a escritura corporal na construção da cena.

Na encenação de O Disfarce do Ovo ${ }^{3}$, objeto de reflexão do presente texto, trabaIhamos a partir de dois contos de Clarice Lispector: "Legião Estrangeira", que possui

\footnotetext{
${ }^{1}$ Membro do Coletivo Teatro Dodecafônico e Professora da Universidade Federal de Uberlândia

2 "A ideia de coletivo de artistas é muito comum nas artes plásticas, de onde as artes performáticas tomaram o conceito emprestado. (...) ...escolhe-se um foco de interesse, um local para ocupar, ou tema agregador de grupos e artistas "avulsos" e num tempo pré-estabelecido desenvolve-se o trabalho." (VELOSO, 2008)

${ }^{3}$ Ficha Técnica: Encenação: Verônica Veloso. Co-encenação: Paulina Caon. Intérpretes criadoras: Beatriz Cruz e Gabriela Cordaro. Preparação corporal: Verônica Veloso e Paulina Caon. Espaço cênico: Renata Velguim.
} 
narrativa clara, com começo, meio e fim; e com "O ovo e a galinha", que aproxima-se mais de um ensaio estilístico do que de um conto propriamente dito, uma vez que não conta uma história, nem mesmo de maneira fragmentada. Clarice disserta sobre um ovo, observando-o de muitos ângulos e tecendo considerações a seu respeito.

Ao longo de seu processo criativo, percebemos que não pretendíamos fazer uma adaptação do texto ou das imagens suscitadas por ele para o teatro, mas um estudo criativo dos contos, a partir dos quais geramos uma encenação que se constituiu como uma resposta do Coletivo ao universo da autora. Dessa percepção surgiu a necessidade de acrescentar o subtítulo, uma reação a Clarice Lispector, ao título da encenação, O Disfarce do Ovo.

Neste texto, visamos refletir sobre a delimitação da ideia de reação como modo de operar na escritura da cena teatral que emergiu da prática estabelecida pelo Coletivo Teatro Dodecafônico. Para tanto, compartilharemos alguns procedimentos utilizados no processo da encenação, refletindo sobre seus sentidos na criação teatral contemporânea.

\section{A construção de uma reação}

Estabelecer limites, classificar, definir, delimitar, fixar: ver é dar forma ao pensamento e esgotar, de alguma maneira, o instante fugaz em que algo é livre para ser qualquer coisa, antes de ser capturado pela linguagem, pelo discurso, pela autoridade pesada daquilo que diz "isso é...". Ver, portanto, pode ser de fato perigoso, e o "ovo é coisa que precisa tomar cuidado", já avisa o(a) personagem do conto nas primeiras páginas. (Livia Almendary)

O processo de trabalho do Coletivo na interação com o texto de Clarice Lispector partiu de duas ações básicas: uma prática corporal para a consciência do movimento, gerando a construção de partituras ou jogos pautados em elementos formais da linguagem corporal; e a coletânea de impressões, citações, outros textos conectados ao universo dos dois contos de Clarice Lispector. Tal coletânea nos levou a delimitar como foco a investigação do feminino na contemporaneidade e, mais especificamente, das referências dele entre as participantes do Coletivo (em sua maioria, mulheres).

Nesse sentido, nossa primeira percepção é a de que a reação tem a ver com uma atitude de investigação ligada à figura do colecionador, presente na obra de Walter Benjamin (1994, 1998). Cada artista do Coletivo passa a agir como um colecionador, aquele que segundo Benjamin tem a capacidade de renovar o mundo: "[...] para o

Figurino: Djöh Wakabara. Concepção de luz: Taty Kanter. Vídeos: Marina Bastos. Audiocenografia: Felipe Julian. Arte-gráfica e fotografia: Renata Velguim. Produção: Coletivo Teatro Dodecafônico. 
colecionador autêntico a aquisição de um livro velho representa o seu renascimento." (BENJAMIN, 1987, p.229).

\begin{abstract}
Benjamin nos remete aqui [no prefácio sobre o Drama Barroco] à noção clássica de história naturalista, que retoma o termo grego de história [...], um termo que designa uma atividade de exploração e de descrição do real sem a pretensão de explicá-lo [...] A história repousa numa prática de coleta de informações, de separação e de exposição de elementos, [...] mais aparentada àquela do colecionador [...] do que àquela do historiador no sentido moderno que tenta estabelecer uma relação causal entre os acontecimentos do passado. (GAGNEBIN, 1999: 09-10)
\end{abstract}

A partir da diversidade de materiais coletados, a atitude do colecionador permite que cada artista destaque da obra original trechos, pensamentos paralelos e referências cruzadas que já podem ser consideradas pequenas reações. Em nosso caso, assim como para Benjamin, não pretendemos reproduzir ou explicar os contos. Reagir à obra significa atualizá-la, multiplicando e renovando os seus sentidos.

Os procedimentos criativos utilizados sistematicamente imbricaram elementos das práticas corporais às referências, algumas delas textuais, trazidas pelas duas atrizes. Em um desses procedimentos, uma exploração de movimentos de expansão e recolhimento, gerou um repertório selecionado de ações que, em seguida, foi friccionada a fragmentos de textos de Lispector sugeridos pela encenadora. Os fragmentos se referiam à amplitude e compressão de espaços e sensações presentes no conto "A Legião Estrangeira". A enunciação dos textos era submetida às qualidades de movimento e sensação corporal que a realização daquela partitura causava, alterando sutil ou radicalmente os sentidos do texto que era enunciado. Em outra situação, a encenadora "encomendou" uma tarefa às atrizes - produzir uma partitura interagindo com o objeto central de "O Ovo e a Galinha" (um ovo) e escolher frases do conto para dizer junto da partitura. Para produzi-la, a encenadora propôs uma série de verbos, pelos quais elas teriam de passar na composição da mesma (mostrar, aproximar e distanciar-se, acoplar, esconder, transformar).

Nos dois casos, fica clara que nossa apropriação do material literário não é nem pautada na fábula, nem no texto como um todo. Cabe, portanto, nos determos brevemente sobre o modo como o Coletivo se propõe a lidar com a matéria textual em seu trabalho.

Os textos presentes no roteiro, no ato de sua emissão, podiam ser ditos (por um ou mais emissores), ouvidos (pois os emissores não estavam presentes) ou lidos (no caso de textos apresentados graficamente)... A matéria textual chega a níveis de grande fragmentação, resultando em estilhaços de texto. (VELOSO, 2009: 159) 
Ou seja, o Coletivo faz uma utilização assumida de fragmentos, sem a preocupação de "encenar" ou tomar o texto todo como ponto de partida para a criação. O fragmento se torna um modo de abordagem da obra, que nos permite aprofundar a exploração das camadas de sentido em diferentes retomadas de jogo e/ou cena. Conforme Maria Lucia Pupo (2005) reflete, em diálogo com autores franceses, isso possibilita a jogadores e público fazerem uma apropriação livre da forma e conteúdo do texto, sem o pressuposto de que se deve ter a mediação de um cabedal de conhecimentos anteriores e imprescindível para a leitura da obra. Além disso: "O procedimento da fragmentação... remete certamente à impossibilidade contemporânea de um olhar totalizante sobre um mundo no qual as certezas não mais parecem evidentes." (PUPO, 2005: 27).

Mais ainda, além de partir de fragmentos, busca-se alimentar o processo de referências diversas trazidas individual ou coletivamente, como dissemos há pouco, o que traz à tona textos e ações claramente inexistentes na obra original. Os workshops ${ }^{4}$ foram ricos nesse aspecto. Na etapa final do processo de criação da peça, a encenadora pede que cada atriz prepare uma improvisação a partir de um quadro do roteiro de encenação ainda não trabalhado: um deles se intitulava "Ofélia Maria dos Santos Aguiar" - referência clara à criança presente em um dos contos; o outro se intitulava "O pinto" - animal presente no mesmo conto. Uma das atrizes trouxe uma sequência de ações pelo espaço em que utilizava textos próprios, escritos anteriormente por ela a partir de suas percepções da infância e situações vividas com outras crianças. A outra atriz trouxe uma espécie de performance em que estava "embrulhada" em plástico bolha e "nascia" de dentro dele durante a execução de um áudio retirado do youtube, que narrava o nascimento de pintinhos em fazenda no interior do Mato Grosso. Tais dispositivos propostos pelas intérpretes do processo formam uma pletora (LEHMANN, 2007) de referências cruzadas, que apenas remetem a objetos e imagens dos contos. Ampliam-se visões e percepções sobre o texto original e são acrescentadas outras possibilidades de textos para a encenação.

Também exploramos a possibilidade da audição de textos ao longo da encenação. Percebemos no conto "A Legião Estrangeira" a presença forte de "regras" e "normas" da vida feminina, repetidamente enunciadas pela personagem Ofélia (uma

\footnotetext{
${ }^{4}$ Procedimento de trabalho no qual uma cena é encomendada aos atores, que apresentam suas leituras de trechos do texto que consideram caros, temas ou estímulos dados pela encenadora. Tais cenas podem trazer colaborações textuais, imagéticas, audiovisuais, etc.
} 
criança) para a personagem da escritora (uma adulta). A partir disso, passamos a coletar outras frases "normatizadoras" (por vezes provérbios, por vezes frases ditas no processo de educação das filhas) presentes em nossa memória e/ou em depoimentos de outras mulheres adultas. Essas frases passaram a ser experimentadas pelas atrizes enquanto faziam uma trajetória com ações de limpeza doméstica pelo espaço. Ao longo do processo criativo, essas frases foram transformadas em um áudio, que estimulava a ação das atrizes e sua enunciação das mesmas frases (repetindo, fazendo associações livres a partir do que ouviam, etc.). A cena foi criada por sobreposição, remetendo a procedimentos cinematográficos de montagem, que também fazem parte da práxis do Coletivo.

Um último modo de lidar com os textos em cena foi sua exposição no espaço.

A presença do texto grafado, para ser lido, evidencia o tratamento dado ao texto, como materialidade visual e sonora, no que tange à musicalidade do texto. Ao ser transformado em imagem, o texto é liberado de interpretações psicologizantes e seu estatuto é revelado como presença visível e não só audível. O texto visto em cena é uma citação da experiência literária. Embora não entre em contato com o texto por meio do suporte papel, o ato da leitura, da decodificação dos signos linguísticos convida o espectador a complementar a cena com imagens formuladas a partir de sua enciclopédia pessoal, como diz Umberto Eco. (VELOSO, 2009: 172)

Em certa cena, que costumamos chamar de "parede", as atrizes realizavam uma partitura de movimentos nascida de uma sequência de aquecimento feita no chão (deitadas de costas). De início, as duas realizavam as partituras em paralelo ocupando um espaço pequeno (um recorte de chão ou de parede), aparentemente isoladas em seus universos. Várias leituras eram sugeridas pela imagem: a solidão da vida contemporânea, alguém que não consegue dormir na cama. Conforme a cena foi sendo burilada, algumas regras de jogo foram estabelecidas - o cruzamento de olhares entre elas, gerava reinício da partitura, a aceleração de movimentos devia ocorrer em algum momento e contaminar ambas e, por fim, elas deveriam se tocar e re-explorar fragmentos da partirtura a partir do estímulo do contato corporal com a outra. Passamos a buscar uma trilha sonora que dialogasse com a cena, de modo a ser mais um elemento de jogo. Por fim, foi feita uma seleção de textos que era exibida, como uma legenda, próximo ao recorte espacial, no qual a cena é realizada (acima ou abaixo das atrizes) e, por vezes, sobre seus corpos. Tais opções dependeram dos diferentes locais, nos quais as encenações foram instaladas, desde sua concepção e estréia, em 2008 e 2009 respectivamente. 
Retomando o tema da exibição de textos escritos em cena, nossa idéia é propor e dar espaço para o espectador fruir - "[...] o sujeito lendo pode ver, farejar, tatear o que a matéria da palavra coloca à disposição" (OLIVEIRA, 2009: 111). Isso leva também à concepção e abordagem geral do Coletivo Teatro Dodecafônico em relação ao texto nossa apropriação é livre, criativa e multiplicadora de sentidos e, para tanto, precisamos de uma relação sensorial, corporal com o texto, em sua materialidade e em seus sentidos.

Para finalizar essa etapa, cabe abordar o processo de encenação. Reagir é montar, sobrepor, criar em camadas, como fica claro no exemplo da cena da "parede" - articularam-se por sobreposição duas partituras, um espaço, uma música e, por fim, os textos. O mesmo processo pôde ser percebido na cena dos "comandos" em que a trajetória de ações de limpeza das atrizes é posta em diálogo com o áudio e, mais tarde, com o público, que é alocado dentro do espaço de jogo das atrizes, sendo "faxinados" pelas mesmas também. $O$ procedimento de montagem, nesse caso, parece nos auxiliar a compreender a ideia e forma da reação - uma série de visões, sensações, ações que compõem muito mais respostas ao universo formal e imaginário de Clarice Lispector do que uma tentativa de adaptação às supostas intenções do autor.

O último exemplo também nos ajuda a perceber o modo de escritura cênica do Coletivo. Ele se constitui no entrelaçamento de cenas que propõem experiências sensoriais (audiovisuais, táteis, espaciais, temporais) que atravessam os corpos de atores e espectadores. A construção da dramaturgia continua dialogando com o cinema a partir da ideia de roteiro, que leva em conta a circulação de sentidos (RYNGAERT, 2009). Algumas cenas se associam por afinidade temática ou temporal, no que se refere ao momento da peça no qual tal cena deve acontecer. Por exemplo, a cena já citada da "parede" em geral (nas diferentes temporadas) foi posicionada na abertura da encenação, pois parece introduzir o público à poética do Coletivo, explicitando a experimentação formal, a corporalidade e a multiplicação de sentidos desde a abertura da encenação. A cena do "nascimento do pinto", por seu caráter quase epifânico, sempre é posicionada ao final da peça. Entretanto, o roteiro se descreve principalmente segundo a geografia do espaço onde a encenação se instala, ou seja, os percursos espaciais e não fabulares. Assim sendo, as cenas funcionam como peças que são combinadas e recombinadas em diferentes ordenações, mantendo-se apenas pequenos blocos afins, conforme a encenação muda de local de apresentação e conforme novas cenas surgem no processo. 


\section{Considerações finais}

A adaptação - fixação, explicação, tradução - seria trair o próprio objeto de partida, seria como "chamar de branco aquilo que é branco" e, justamente por isso, "destruir a humanidade"... pode-se dizer 'um rosto bonito', mas quem disser 'o rosto' morre; por ter esgotado o assunto". Reagir, pois, para não esgotar. (Livia Almendary)

Ao utilizar o termo reação, buscamos nomear um modo de operar da encenação junto ao texto literário, que talvez também seja praticado em outros contextos. Em nosso modo de criar a partir do estímulo literário ocorre uma espécie de processamento, sedimentação individual e coletiva da obra, que compõe o processo de reação. De certo modo, situamo-nos no campo da recepção (DESGRANGES, 2003; ZUMTHOR, 2007): ao ler Clarice Lispector, os criadores do Coletivo trazem consigo suas experiências estéticas, sociais, culturais anteriores e debruçam-se em uma investigação conduzida pelos parâmetros propostos pela encenação. Assim, nosso primeiro exercício é de recepção desse texto. Recepção que, como pontua Zumthor, inclui a performance no próprio ato de leitura. A reação como modo de criação sugere uma espécie de explicitação do processo de recepção do Coletivo, que revela uma constelação de imagens, ações e sonoridades, e engendra, nesse percurso, novos sentidos ao texto original, um outro texto, agora cênico. A encenação, a composição de uma dramaturgia da cena a partir desses materiais, burila e refina tal processo de recepção, de maneira que o público não o acesse em estado bruto. Em diálogo com a cena teatral contemporânea, na estruturação da encenação, a figura da pletora permanece - conjunto de elementos díspares, referências cruzadas, cuja coerência não passa pela linearidade da fábula ou pela construção de unidades espaciais, dramáticas e nem mesmo pela composição de personagens. Os espectadores, ao fruir, terão novo exercício de recepção, desdobrando novas reações e sentidos a partir do contato com a encenação.

Ao longo do processo de encenação e temporadas, percebemos que a escrita de Clarice, de certo modo, também é uma reação a sua própria experiência no mundo.

Os primeiros críticos literários que escreveram sobre Clarice Lispector notaram que sua prática discursiva retirava o sentido comum das palavras para moldá-las às suas necessidades de expressão. A autora não utilizava a linguagem como um dispositivo para ordenar o mundo, e sim como elemento de transgressão, de potência... Clarice tentava a façanha de escrever sem esgotar ou limitar em apenas uma as "mil faces secretas sob a face neutra" de uma palavra; escrevia para multiplicar os sentidos do mundo, e não para reduzi-los. (ALMENDARY).

Assim como Lispector escreve a partir de sua corporeidade e presença no mundo, nossa reação se dá a partir de um corpo a corpo com suas palavras e de um corpo a 
corpo com nossa presença no mundo atual. Nesse sentido, dialogamos com Oliveira (2009) quando aponta diferentes potências de interação com a literatura:

\footnotetext{
O texto se faz presente se o leitor se presentifica nele, ou seja, estar exposto ao texto significa deixar-se conduzir por ele, deixar que seu ritmo se imprima naquele que lê, deixar que as palavras o contagiem... se se atravessa o texto a pé, caminhando em suas entrelinhas e texturas, as palavras em suas linhas (de fuga e excêntricas) vão se tatuando por todo o corpo, como se, ao marcar em si o texto, fosse possível o sujeito leitor se ver sob um novo ponto de vista, uma mirada estranha, estrangeira.

Sobrevoar um espaço ou um texto... acarreta em estar ausente dele, em uma distância que elimina o detalhe, o singular, uma distância que generaliza, que leva a uma destituição da experiência, ao colocar à margem a corporeidade, o viés sensorial do acontecimento. (OLIVEIRA, 2009: 91)
}

Assim, interessa ao Coletivo Teatro Dodecafônico essa travessia de afetações mútuas, em que se multiplicam impressões e experiências na composição de uma outra obra (cênica) a partir da interação com o texto literário, sem ter a pretensão de explicá-lo, reduzi-lo a uma única visão. Reagir, pois, para não esgotar.

\section{Referências Bibliográficas}

ALMENDARY, Livia. Olhar, apalpar com olhos nômades ou Uma reação ao disfarce do ovo. In: http://teatrododecafonico.blogspot.com, acesso em 25-05-11.

BENJAMIM, Walter. Obras Escolhidas I: Magia e técnica. Arte e Política. São Paulo: Brasiliense, 1994.

Obras Escolhidas II: Rua de mão única. São Paulo: Brasiliense, 1987.

GAGNEBIN, Jeanne-Marie. História e Narração em Walter Benjamin. São Paulo: Ed. Perspectiva, 1999.

LEHMANN, Hans-Thies. Teatro Pós-dramático. São Paulo: Cosac Naif, 2007.

OLIVEIRA, Eliana Kefalás. Corpo a corpo com o texto literário. Campinas, 2009. Tese de Doutoramento.

PUPO, Maria Lucia de Souza Barros. Entre o Mediterrâneo e o Atlântico, uma aventura teatral. São Paulo: Perspectiva, 2005.

RYNGAERT, Jean-Pierre. Jogar, representar. São Paulo: Cosac Naif, 2009.

VELOSO, Verônica Gonçalves. Jogos do Olhar - procedimentos cinematográficos para a composição da cena teatral. São Paulo, ECA-USP, 2009. Dissertação de mestrado.

Grupo ou Coletivo - uma questão de tempo. Anais do V Congresso ABRACE, 2008.

ZUMTHOR, Paul. Performance, Recepção, Leitura. São Paulo: Cosac Naif, 2007. 